\title{
Incidental intracranial saccular aneurysm in a patient with post- Covid-19 headache: What to do with the incidentaloma?
}

\author{
Marcelo Moraes Valença ${ }^{1}$ (D) Alberto Henrique Torres Trindade da Silva² (D) Renan Furtado de Almeida \\ Mendes $^{3}$ (D) Pedro Henrique Pereira de Andrade ${ }^{1}$ (D) Ubiratan Alves Viturino da Silva ${ }^{1}$ (D) Déborah Emmily \\ de Carvalho ${ }^{2}$ (D) Laécio Leitão Batista ${ }^{1}$
}

${ }^{1}$ Universidade Federal de Pernambuco, Recife, Pernambuco, Brazil.

${ }^{2}$ Universidade de Pernambuco, Recife, Pernambuco, Brazil.

${ }^{3}$ Universidade Federal da Paraíba, João Pessoa, Paraíba, Brazil.

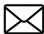

Marcelo Moraes Valença

mmvalenca@yahoo.com.br

Edited by:

Mario Fernando Prieto Peres

\section{Introduction}

n the last decades, there was a growing increase in incidentalomas. ${ }^{1-6}$ In the radiological investigation of patients with headaches, it is not infrequent to find incidentalomas. ${ }^{7-8}$ Incidentaloma is classically defined when, during a radiological investigation, a tumoral lesion is identified, and such lesion is not related to the clinical condition that justified the request for the examination. In other words, it was an incidental finding, i.e., a lesion found by coincidence without any clinical symptoms or suspicion. ${ }^{9}$

The term incidentaloma also serves to designate other lesions found incidentally, such as in the case of an aneurysm. Unruptured intracranial saccular aneurysms develop in cerebral arteries over months or years and are rarely symptomatic. ${ }^{10.14}$ Eventually, during an imaging evaluation, these brain aneurysms are discovered. For many of these aneurysms, the chosen approach is conservative, depending on the size, location, associated diseases, risk of bleeding, family history, among other factors that modify the risk of rupture..$^{13,15}$ If the approach is conservative, it is essential to follow up with serial reassessment by angiography (e.g., MR angiography).

Approximately $2-4 \%$ of the population harbours an unruptured intracranial aneurysm ${ }^{16-21}$, and up to $30 \%$ and $42 \%$ of these patients may have multiple aneurysms in imaging or autopsy studies, respectively. ${ }^{22-23}$ With increased utilization of noninvasive imaging, the detection of these aneurysms has become very common, the so-called incidentaloma.

The discovery of an incidental unruptured intracranial saccular aneurysm implies decision-making strategy about its treatment, either conservative or surgical (open or an endovascular approach), depending on the size, location, angioarchitecture of the aneurismal sac, associated dis

eases, age, risk of bleeding, family history, among other factors that may modify the risk of rupture. ${ }^{13,15}$ If the approach 
is conservative, following up the aneurysm with a serial reassessment by magnetic resonance angiography (MRA) is essential. This article will discuss the best management of an elderly patient with an incidentally discovered saccular aneurysm originated in the left middle cerebral artery (MCA).

\section{Case report}

An 83-year-old woman in January 2021 developed persistent headache and decline in cognitive functions that appeared after the acute onset of Covid-19. She is a regular smoker and has hypertension treated with bisoprolol, oral

anticoagulants (rivaroxaban) to control cardiac arrhythmia, and oral rosuvastatin to control dyslipidemia. She denied a family history of a brain aneurysm. She was evaluated with computed tomography (CT), magnetic resonance imaging (MRI), and digital angiography to investigate the causes of symptoms (Figures 1 and 2). CT scan showed an image compatible with aneurysmal dilatation in the left middle cerebral artery bifurcation, confirmed by contrast magnetic resonance angiography (Figure 1). According to digital angiography, the saccular dilatation had the following dimensions: $7.7 \times 4.7 \times 3.5 \mathrm{~mm}$, with a neck measuring $2.5 \times 2.4 \mathrm{~mm}$ (Figure 2). In this case, after evalvating the advantages and disadvantages of conservative versus preventive surgical intervention (clipping or coiling), considering the patient's advanced age and expectations, associated morbid conditions, we decided on a non-surgical approach, with conservative measures such as blood pressure control, use of beta-blockers, statin, and follow-up by CE-MRA.

\section{Comments}

Despite advancements in the management of subarachnoid hemorrhage (SAH) due to aneurysmal rupture, overall case fatality is quiet high. (40-60\%). ${ }^{14}$ Perhaps, for this reason, patients harboring unruptured intracranial aneurysms have performed preventive surgical intervention for many decades to eliminate any conceivable aneurysm rupture.

Accordingly, managing of the patient with unruptured intracranial aneurysms ${ }^{24}$ remains a challenge with medical, ethical, and legal implications. Some key questions remain: what is the risk of rupture for a specific aneurysm in a patient in which specific risk factors can be identified? So, we should consider important clinical and morphological points before deciding when and how an accidental aneurysm should be treated.

The prospective arm of the ISUIA ${ }^{14}$, one of the most extensive studies examining rupture risk of unruptured asymptomatic intracerebral aneurysms, examined especially patients with no previous history of subarachnoid hemorrhage that location and size are the major key points to consider in terms of rupture risk. A majority of ruptured aneurysm shows diameter less than $7 \mathrm{~mm}$, coming up the theory that faster the aneurysm grows, soon will be ruptured. Recently, Liu and coworkers ${ }^{9}$ monitoring unruptured intracranial aneurysms based on a volumetric analysis found that a group of the aneurysm can present with accelerated growth rate mainly depending on the location, suggesting that linear measurements could be fallible in predict a warning aneurysm behavior.

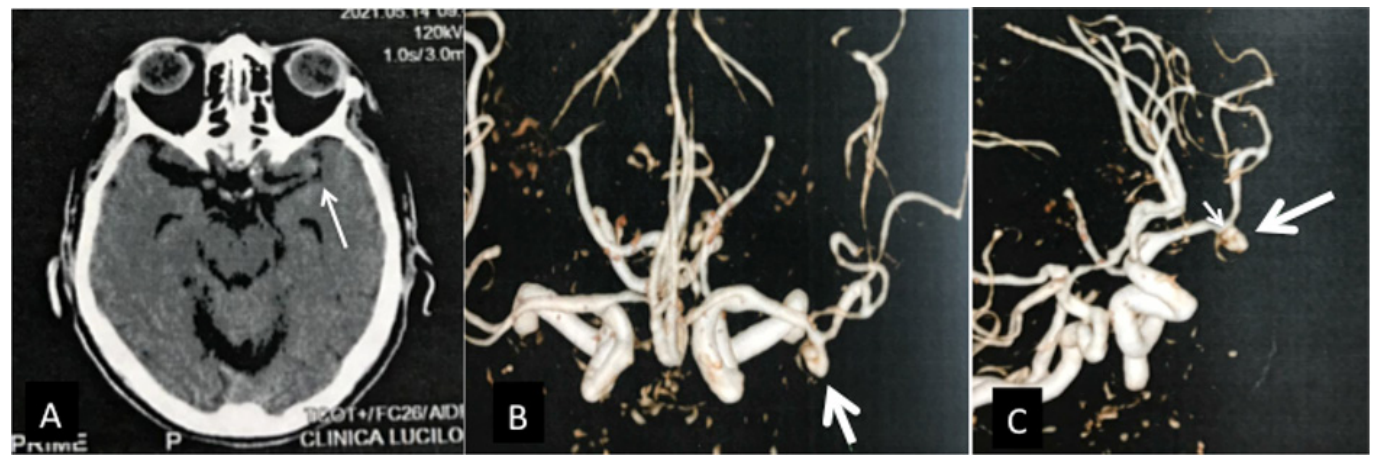

Figure 1. (A) Brain axial CT scan revealed a saccular hyperdensity on the distal left middle cerebral artery (MCA) (arrow); (B) 3D CE-MRA reconstruction on frontal and (C) oblique views showing a $7.1 \mathrm{~mm}$ lobulated saccular aneurysm (arrows) on the bifurcation of the MCA. Lobulation on the aneurismal wall is seen. 

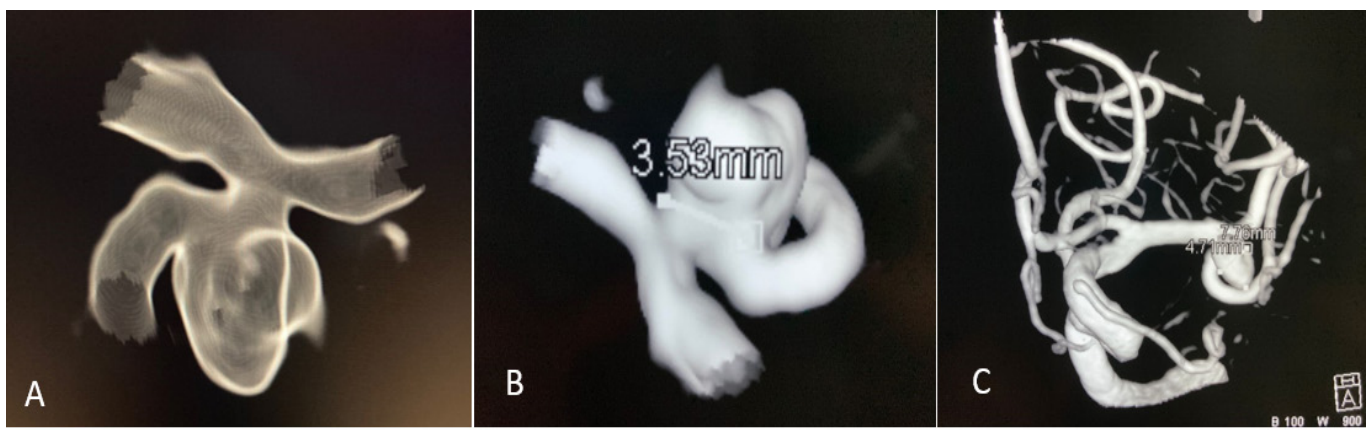

Figure 2. Lobulation is observed in the aneurismal wall.

Age is another crucial point to be taken into consideration for a decision-making process. Although increasing age after 50 does not substantially impact the risk of rupture, preventive surgical intervention brings an additional benefit to morbidity and lethality rates, regardless of whether one chooses to endovascular or open surgery. ${ }^{15}$

In Table 1 are listed meta-analysis studies that evaluated different conditions that may modify the risk of rupture of a still unruptured intracranial aneurysm.

Table 1. Published meta-analyses on risk factors for aneurysm growth

\begin{tabular}{|c|c|}
\hline Risk factor for aneurysm growth & Studies \\
\hline Smoking & $\begin{array}{l}\text { Jin et al. }{ }^{25} \text {; Backes et al. }{ }^{26} \text {; Wermer } \\
\text { et al. }{ }^{27}\end{array}$ \\
\hline Age $>70$-years-old & Brinjikji et al. ${ }^{28}$ \\
\hline Arterial hypertension & Backes et al. ${ }^{26}$; Wermer et al. ${ }^{27}$ \\
\hline Woman & $\begin{array}{l}\text { Jin et al. }{ }^{25} \text {; Backes et al. }{ }^{24} \text {; Brinjikii } \\
\text { et al. }{ }^{28} \text {; Wermer et al. }{ }^{27}\end{array}$ \\
\hline Aneurysm size $>7 \mathrm{~mm}$ & Brinjikji et al. ${ }^{28}$; Wermer et al. ${ }^{27}$ \\
\hline Middle cerebral artery aneurysm & Brinjikji et al. ${ }^{28}$; Wermer et al. ${ }^{27}$ \\
\hline
\end{tabular}

Using longitudinal analysis of the aneurysm volume, Liu and coworkers ${ }^{29}$ demonstrated in a series of 112 aneurysms in 95 patients (the mean follow-up time was 4.0 years.) with UIA that there was evident growth at one year of follow-up in $8 \%$ of cases. $36 / 112(32 \%)$ of the aneurysms exhibited noticeable growth during the study, and $11 / 36$ (31\%) aneurysms with noticeable change had an episode of abrupt growth (only 11 of the 112 aneurysms (9.8\%) presented an episode of sudden growth). ${ }^{29}$ The relative growth rate was dependent on age and the location of the aneurysm, with aneurysms of the anterior cerebral artery showing the fastest growth rate of $4.07 \%$ per year. In this study, aneurysms of the middle cerebral artery presented an annual growth rate of $1.41 \% .{ }^{29}$

A recent study ${ }^{11}$ evaluated the role of statins in unruptured intracranial aneurysm growth and rupture, observing whether atorvastatin (20 mg daily) was associated with aneurysm growth or rupture in patients with less than $7 \mathrm{~mm}$ aneurysms. Among the 1.087 enrolled patients, 489 (45\%) took atorvastatin (mean follow-up duration of $33.0 \pm 12.5$ months). Current smoker and uncontrolled hypertension were associated with aneurysm rupture, whereas atorvastatin use was not. The authors concluded that unruptured aneurysms sized 5 to $<7 \mathrm{~mm}$ and uncontrolled hypertension both were associated with a high growth rate, whereas atorvastatin was associated with a reduced growth rate."

In another study ${ }^{30}$, chosen aneurysm locations (i.e., anterior communicating artery, posterior communicating artery, and middle cerebral artery) and an aneurysm size of 5 to $<7$ $\mathrm{mm}$ were associated with a high risk of aneurysm growth, whereas aspirin and well-controlled blood pressure were associated with a low risk of growth. However, in high-risk patients ( $>1$ risk factor), the cumulative annual growth rates were as high as 40.0 and 53.3 per 100 person-years. ${ }^{30}$

It is worth remembering the headaches associated with aneurysmatic rupture with subarachnoid hemorrhage due to the risk of death due to the lack of an accurate and immediate diagnosis. Headache associate with aneurysm rupture or aneurysm expansion presents as a sudden-onset, high-intensity explosive thunderclap headache, usually occurring during physical exertion. Intracranial aneurysms can simulate a primary headache as well, such as cluster headache. In this context, it is recalled that every patient with cluster headache should be investigated by imaging, including an MRA and cerebral digital subtraction angiography. ${ }^{31}$

Regarding the choice of a conservative management of UIA, results from two studies support this decision. Lawson and colleagues ${ }^{32}$ built a methodological model to compare the probability of poor outcomes from intervention (clipping and endovascular) compared to the natural history of the aneurysm, as a function of age and aneurysm size, using data from previous studies. Poor outcomes included discharge to a skilled nursing facility, long-term care facility, 
hospice, or in-hospital death. They demonstrated a poor outcome for both clipping or coiling beyond the age of 80 years. Considering the patient's characteristics reported here, an advantage in intervention chose is observed in only one of the four comparisons made, in which endovascular treatment would show benefit up to 86 years old.

Additionally, at the PHASES score study ${ }^{13}$, many of patients with an unruptured intracranial aneurysm derived from six extensive cohort studies, and information was included in a pooled database. They built a model indicating the probability of rupture based on well-known risk factors for aneurysm rupture. The PHASES study incorporated in the evaluation other risk factors, such as age, the maximal diameter and the previous history of subarachnoid hemorrhage. Considering the PHASES score, we calculate a risk of rupture of $2.4 \%$ per year $(95 \% \mathrm{Cl} ; 1.6-3.3)$, considering the sum total of 7 points from a population, hypertension, age, aneurysm size and site, and absence of a history of SAH. Both studies include the patient's history of hypertension and the first includes the history of smoking. As for limitations, the PHASES score considers populations that do not belong to the reality of the case, making the risk of rupture with the application of the score an estimate.

We conclude by commenting on the significant chance to encounter an asymptomatic intracranial lesion during a patient's headache investigation. ${ }^{7}$ Thus, the physician must decide how to treat this incidental finding, which may increase the risk of death.

\section{Conflict of interests: No}

Marcelo Moraes Valença

https://orcid.org/0000-0003-0678-3782

Alberto Henrique Torres Trindade da Silva

https://orcid.org/0000-0003-2356-4426

Renan Furtado de Almeida Mendes

https://orcid.org/0000-0002-9433-7020

Pedro Henrique Pereira de Andrade

https://orcid.org/0000-0002-7701-983X

Ubiratan Alves Viturino da Silva

https://orcid.org/0000-0002-7715-8258

Laécio Leitão Batista

https://orcid.org/0000-0001-5081-2689

Déborah Emmily de Carvalho

https://orcid.org/0000-0002-8068-3598

\section{References}

1. Kebebew E. Adrenal Incidentaloma. $N$ Engl J Med 2021;384(16):1542-1551 Doi:10.1056/ NEJMcp2031112
2. Fujikawa $H$ and Hinata $M$. Splenic incidentaloma on routine chest radiography before admission to a nursing home. BMJ Case Rep 2021;14:e243031 Doi:10.1136/bcr-2021-243031

3. Gokce A, Hatipoglu M, Kandemir NO and Akkas $Y$. Thoracic incidentaloma in a chest computed tomography scan of a patient with COVID-19. Br J Hosp Med (Lond) 2021;82(6):1-3 Doi:10.12968/ hmed.2021.0295

4. Kim YJand LeeKA. Unusual case ofadrenal incidentaloma: pheochromocytoma with acute adrenal hemorrhage. Am J Med Sci 2021;S0002-9629(21):00239-1 Doi: 10.1016/i.amjms.2021.06.008

5. Wang J, Yan H, Huang G, Sun R, Cheng Y, Tian S and $\mathrm{Ma} Y$. Hormone silent giant adrenal incidentalomaadrenal ganglioneuroma: case report and literature review. Rofo 2021;Doi:10.1055/a-1487-6740

6. Sherlock M, Scarsbrook A, Abbas A, Fraser $S$, Limumpornpetch $P$, Dineen R and Stewart PM. Adrenal Incidentaloma. Endocr Rev 2020;41(6):bnaa008 Doi: $10.1210 /$ endrev/bnaa008

7. Valenca MM, Valenca LP and Menezes TL. Computed tomography scan of the head in patients with migraine or tension-type headache. Arq Neuropsiquiatr 2002; 60(3-A):542-547 Doi: 10.1590/S0004282X2002000400005

8. Valença MM. "Incidentalomas" in the investigation of a patient with headache. Headache Medicine 2014;5(1):4-6 Doi:10.48208/HeadacheMed.2014.1

9. Stip E, Miron JP, Nolin M, Letourneau G, Bernazzani O, Chamelian L, ... Lungu O. Incidentaloma Discoveries in the Course of Neuroimaging Research. Can J Neurol Sci 2019;46(3):275-279 Doi:10.1017/cjn. 2018.397

10. Liu X, Haraldsson H, Wang Y, Kao E, Ballweber M, Martin AJ, . . Saloner D. A Volumetric Metric for Monitoring Intracranial Aneurysms: Repeatability and Growth Criteria in a Longitudinal MR Imaging Study. AJNR Am J Neuroradiol 2021;Doi:10.3174/ajnr.A7190

11. Wang J, Weng J, Li H, Jiao Y, Fu W, Huo R, ...Zhao J. Atorvastatin and growth, rupture of small unruptured intracranial aneurysm: results of a prospective cohort study. Ther Adv Neurol Disord 2021;14(1756286420987939 Doi: $10.1177 / 1756286420987939$

12. Weng JC, Wang J, Li H, Jiao YM, Fu WL, Huo R, . . .Zhao JZ. Aspirin and Growth of Small Unruptured Intracranial Aneurysm: Results of a Prospective Cohort Study. Stroke 2020;51(10):3045-3054 Doi:10.1161/STROKEAHA. 120.029967

13. Brinjikji W, Pereira VM, Khumtong R, Kostensky A, Tymianski M, Krings T and Radovanovich I. PHASES and ELAPSS Scores Are Associated with Aneurysm 
Growth: A Study of 431 Unruptured Intracranial Aneurysms. World Neurosurg 2018;1 14:e425-e432 Doi:10.1016/j.wneu.2018.03.003

14. Juvela $S$. Natural history of unruptured intracranial aneurysms: risks for aneurysm formation, growth, and rupture. Acta Neurochir Suppl 2002;82:27-30 Doi:10.1007/978-3-7091-6736-6_5

15. Valenca MM. "Sit back, observe, and wait." Or is there a pharmacologic preventive treatment for cerebral aneurysms? Neurosurg Rev 2013;36(1): 1-9; discussion 9-10 Doi:10.1007/s10143-012-0429-7

16. Abi-Aad KR, Rahme RJ, Syal A, Patra DP, Hudson M, Richter KR, . . .Bendok BR. Quality of Life of Patients with Unruptured Intracranial Aneurysms Before and After Endovascular Coiling: A HEAT Trial Secondary Study and Systematic Review of the Literature. World Neurosurg 2021;146:e492-e500 Doi:10.1016/i. wneu.2020.10.120

17. Akimoto J, Ichimasu N, Haraoka R, Fukami S and Kohno $M$. A case of unruptured aneurysm of the internal carotid artery presenting as olfactory hallucinations. Surg Neurol Int 2017;8:197 Doi:10.4103/sni.sni_134_17

18. Ben-Israel D, Belanger BL, Adibi A, Eesa M, Mitha $A P$ and Spackman E. Innovation in unruptured intracranial aneurysm coiling: At which price or efficacy are new technologies cost-effective? PLOS One 2021;16(8):e0255870 Doi:10.1371/journal. pone. 0255870

19. Boulouis $G$, Rodriguez-Regent $C$, Rasolonjatovo EC, Ben Hassen W, Trystram D, Edjlali-Goujon M, . . Naggara $O$. Unruptured intracranial aneurysms: An updated review of current concepts for risk factors, detection and management. Rev Neurol (Paris) 2017;173(9):542551 Doi:10.1016/j.neurol.2017.05.004

20. Chien A, Callender RA, Yokota H, Salamon N, Colby GP, Wang AC, . . .Hildebrandt MAT. Unruptured intracranial aneurysm growth trajectory: occurrence and rate of enlargement in $\mathbf{5 2 0}$ longitudinally followed cases. J Neurosurg 2019;132(4):10771087 Doi:10.3171/2018.11.JNS181814

21. Damani R, Mayer S, Dhar R, Martin RH, Nyquist $\mathrm{P}$, Olson DM, . . . Investigators SCP. Common Data Element for Unruptured Intracranial Aneurysm and Subarachnoid Hemorrhage: Recommendations from Assessments and Clinical Examination Workgroup/ Subcommittee. Neurocrit Care 2019;30(Suppl 1):2835 Doi:10.1007/s 12028-019-00736-1

22. Goubergrits L, Hellmeier F, Bruening J, Spuler A, Hege HC, Voss S, . . Berg P. Multiple Aneurysms AnaTomy CHallenge 2018 (MATCH): uncertainty quantification of geometric rupture risk parameters. Biomed Eng Online 2019; 18(1):35 Doi:10.1186/s12938-019-0657-y
23. Fung C, Mavrakis E, Filis A, Fischer I, Suresh $M$, Tortora A, . . Petridis AK. Anatomical evaluation of intracranial aneurysm rupture risk in patients with multiple aneurysms. Neurosurg Rev 2019;42(2):539547 Doi:10.1007/s10143-018-0998-1

24. Zhong W, Su W, Li T, Tan X, Chen C, Wang Q, . . .Wang $Y$. Aneurysm Wall Enhancement in Unruptured Intracranial Aneurysms: A Histopathological Evaluation. J Am Heart Assoc 2021;10(2):e018633 Doi: 10.1161/JAHA. 120.018633

25. Jin $D$, Song $C$, Leng $X$ and Han P. A systematic review and meta-analysis of risk factors for unruptured intracranial aneurysm growth. Int J Surg 2019;69:6876 Doi:10.1016/j.ijsu.2019.07.023

26. Backes D, Rinkel GJ, Laban KG, Algra A and Vergouwen MD. Patient- and Aneurysm-Specific Risk Factors for Intracranial Aneurysm Growth: A Systematic Review and Meta-Analysis. Stroke 2016;47(4):951-957 Doi: 10.1161 /strokeaha. 115.012162

27. Wermer MJ, van der Schaaf IC, Algra A and Rinkel GJ. Risk of rupture of unruptured intracranial aneurysms in relation to patient and aneurysm characteristics: an updated meta-analysis. Stroke 2007;38(4): 1404 . 1410 Doi:10.1161/01.STR.0000260955.51401.cd

28. Brinjikji W, Zhu YQ, Lanzino G, Cloft HJ, Murad $M H$, Wang $Z$ and Kallmes DF. Risk Factors for Growth of Intracranial Aneurysms: A Systematic Review and Meta-Analysis. AJNR Am J Neuroradiol 2016;37(4):615-620 Doi:10.3174/ajnr.A4575

29. Liu $X$, Haraldsson $H$, Wang $Y$, Kao E, Ballweber $M$, Martin AJ, ...Saloner D. A Volumetric Metric for Monitoring Intracranial Aneurysms: Repeatability and Growth Criteria in a Longitudinal MR Imaging Study. AJNR Am J Neuroradiol 2021;42(9):1591-1597 Doi:10.3174/ajnr.A7190

30. Weng JC, Wang J, Li H, Jiao YM, Fu WL, Huo R, ...Small Unruptured Aneurysms Study G. Aspirin and Growth of Small Unruptured Intracranial Aneurysm: Results of a Prospective Cohort Study. Stroke 2020;51(10):30453054 Doi: $10.1161 /$ STROKEAHA. 120.029967

31. Valença MM, Andrade-Valença LP, Martins C, de Fátima Vasco Aragão M, Batista LL, Peres MF and da Silva WF. Cluster headache and intracranial aneurysm. J Headache Pain 2007;8(5):277-282 Doi:10.1007/s10194-007-0412-9

32. Lawson MF, Neal DW, Mocco J and Hoh BL. Rationale for treating unruptured intracranial aneurysms: actuarial analysis of natural history risk versus treatment risk for coiling or clipping based on 14,050 patients in the Nationwide Inpatient Sample database. World Neurosurg 2013;79(3-4):472-478 Doi:10.1016/i.wneu.2012.01.038 